Silva, M.L., Perrier, L., Cohen, J.M., Paget, W.J., Mosnier, A., Späth, H.M. A literature review to identify factors that determine policies for influenza vaccination. Health Policy: 2015, 119(6), 697-708

\begin{tabular}{|l|l|}
\hline $\begin{array}{l}\text { Postprint } \\
\text { Version }\end{array}$ & 1.0 \\
\hline $\begin{array}{l}\text { Journal website } \\
\text { Pubmed link }\end{array}$ & $\underline{\text { http://www.healthpolicyirnl.com/article/S0168-8510(15)00101-3/abstract }}$ \\
\hline DOI & $10.1016 /$ j.healthpol.2015.04.006 \\
\hline
\end{tabular}

This is a NIVEL certified Post Print, more info at http://www.nivel.eu

\title{
A literature review to identify factors that determine policies for influenza vaccination
}

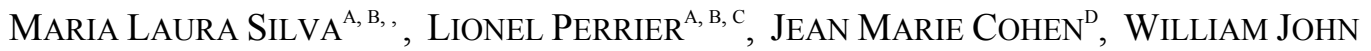 \\ PAGET $^{\mathrm{E}}$, ANNE MOSNIER ${ }^{\mathrm{D}}$, HANS MARTIN SPÄTH ${ }^{\mathrm{F}}$ \\ a Université Lumière Lyon 2, Lyon F-69007, France \\ b CNRS, GATE Lyon Saint-Etienne, Ecully F-69130, France \\ c Direction of Clinical Research and Innovation, DRCI, Léon Bérard Cancer Centre, Lyon, \\ France \\ d Open Rome; Coordination Nationale des Groupes Régionaux d'Observation de la Grippe, \\ Réseau des GROG, Paris, France \\ e Netherlands Institute For Health Services Research (NIVEL), Utrecht, The Netherlands \\ f University Claude Bernard, Lyon 1, EAM 4128 Lyon, France
}

\begin{abstract}
Objectives: To conduct a literature review of influenza vaccination policy, describing roles and interactions between stakeholders and the factors influencing policy-making.

Methods: Major databases were searched using keywords related to influenza vaccination, decision-making and healthpolicy. Titles and abstracts were screened according to defined criteria using independent reviewers. Selected articles were analysed and compared against a checklist.

Results: 342 papers were identified, but only 111 included. A wide range of countries was represented in articles published in 1994-2012. We identified numerous stakeholders at the national and international level and found a variety of interactions between them. Using these data, we suggest a scheme for the most important stakeholders and their interactions. Determinants of policymaking were mainly related to the vaccine/disease, political-economic context, and stakeholders communication. The most relevant evidence was clinical/epidemiological studies. After the 2009 pandemic: the importance of mathematical modelling and ethical issues was greater; and the need for better communication between stakeholders was emphasised.

Conclusions: The relevance of evidence and factors influencing policy-making varied between countries, according to complex interactions between the stakeholders involved at different levels of decision-making process. These interactions remain unclear, especially at national level, where the most important influenza policy decisions are made. To better define and understand
\end{abstract}


Silva, M.L., Perrier, L., Cohen, J.M., Paget, W.J., Mosnier, A., Späth, H.M. A literature review to identify factors that determine policies for influenza vaccination. Health Policy: 2015, 119(6), 697-708

the exact interactions and use of evidence, we recommend undertaking future qualitative studies at national level using small number of countries.

\section{HighLIGHTS}

- We analyse 111 articles related to decision-making on influenza vaccination policy.

- We assess stakeholders' interactions, information used and factors of influence.

- The complex interaction between stakeholders is presented in a holistic scheme.

- The most relevant evidence for policy-making is clinical and epidemiological studies.

- Models, economic studies and ethics have greater importance since the 2009 pandemic.

\section{BACKGROUND}

The important medical and economic burdens of influenza to society, including the decline of major physical functions resulting in direct costs (i.e.: hospitalizations) and indirect costs (i.e.: loss of productivity) [1] and [2], require that policy-makers provide strategies for prevention and control, such as vaccines. The scarcity of health resources calls for policy-makers to set priorities for influenza vaccination [3] and [4]. There are only a few studies that have investigated influenza vaccination policy-making in seasonal and pandemic contexts. For example, the pandemic context is handled with preparedness plans, previously devised to minimise uncertainty [5]. However, many factors can influence the development of these policies, such as time constraints for the decision-making, lack of real-time information and communication between multiple levels of public health. Moreover, political factors and logistics can impact the policy-making [5] and [6]. Policies developed for seasonal influenza are regularly used as the basis for pandemic plans [7]. They are often established in accordance between the government, policymakers, and programme managers with the help of National Immunization Technical Advisory Groups [8] and [9].

Seasonal influenza affects the worldwide population every year, while pandemic influenza is an unpredictable threat. According to the World Health Organization (WHO), annual epidemics result in 3-5 million cases of severe illness and 250-500 thousand deaths worldwide [10]. Following the WHO recommendations for the prevention and control of influenza, more than $40 \%$ of global nations currently include vaccinations in their public health policies [11] and [12]. However, a large debate has developed about the evidence used, transparency of the decision-making process, and role of the institutions involved [13], [14] and [15]. Even though influenza studies have increased after the last pandemic (influenza A(H1N1)pdm09 virus), investigations concerning influenza vaccination policy-making are still scarce.

The chain of influenza vaccination policy-making has four main segments: vaccination recommendations, vaccine composition (strain selection), vaccine license (market authorisation) and vaccine funding (purchase and reimbursement). Previous 
Silva, M.L., Perrier, L., Cohen, J.M., Paget, W.J., Mosnier, A., Späth, H.M. A literature review to identify factors that determine policies for influenza vaccination. Health Policy: 2015, 119(6), 697-708

literature reviews have usually focused on vaccination recommendations: the revision of target groups (i.e. inclusion of pregnant women, certain chronic diseases, healthy working adults, children at scholar age, and healthcare workers) [16], [17], [18], [19], [20] and [21] and the outcomes of the vaccination campaign (i.e. vaccine coverage and the effectiveness of influenza vaccine campaigns) [22], [23] and [24]. Few reviews have investigated other segments of the chain. Additionally, most of the studies available have investigated pandemic contexts only, though it is widely known that the seasonal influenza policy is crucial for pandemic preparedness. Therefore, policy-makers and stakeholders might have difficulties in developing a holistic overview of the decision-making process because the literature available is frequently fragmented and focused only on pandemics.

To bridge this gap, we conducted a literature review aimed at providing a general overview of influenza vaccination policy-making at the global and national levels, describing: (1) roles, relationships, and interactions of the stakeholders involved in the policy chain and (2) the information used to develop these policies and possible factors that influence these decisions.

This literature review provides a general picture, as well as global overview of policies in several countries. It is also an important prologue for further work in this field. The results of this review are intended for policy-makers at the national level, to improve the decision-making process and its transparency.

\section{METHODS}

The main electronic databases were used for this study: Web of Science, Google Scholar, PubMed, EconLit, HEED, and The Cochrane Library. No restrictions on the date or location were applied. A combination of the following search terms was used (the detailed search strategies used for each database can be found in Annex 1):

-Influenza vaccines;

-Vaccinations AND influenza;

-Decision support techniques OR decision making;

-Policy OR public health OR public health administration OR health policy OR public policy OR management.

Papers without abstracts and where the full text was written in a language other than English, French, Spanish, German, Italian, or Portuguese were excluded. Using a checklist, the studies were screened, selected, and the data were extracted. The data recorded comprised: the first author, year of the study, influenza context (pandemic or seasonal), segment of the influenza policy chain investigated, actors, institutions, stakeholders involved and the interactions between them, information used to develop the policies, and factors that influenced this process. Papers were only included if they met the following criteria:

(i)Presence of macro level decision-making (at the community, regional, national, supranational or international levels) regarding the influenza vaccination policy chain; 
Silva, M.L., Perrier, L., Cohen, J.M., Paget, W.J., Mosnier, A., Späth, H.M. A literature review to identify factors that determine policies for influenza vaccination. Health Policy: 2015, 119(6), 697-708

(ii)Description of the stakeholders (actors and shareholders) involved in this decision;

(iii)Description of the information used during the decision making process was assessed.

We also searched for documents published on the websites of widely recognized organizations that play a major role in influenza vaccination policy, such as the US Centers for Disease Control and Prevention (CDC) reports, European ECDC advice, and WHO bulletins. These documents were only used for discussion.

The information (i.e.: scientific studies, grey literature, ethics, logistics) that influenced the decision process was identified in each article. The data were grouped by theme (i.e.: morbidity/severity, cost-analysis/economic models). We then created information and factor categories using terms frequently employed in the literature (i.e.: epidemiology, economic studies). The degree of importance assigned to the categories developed was established by the number of papers that mentioned each category (Annex 2). Therefore, our findings are presented based on these categories and their importance, illustrated with examples of specific papers.

The papers obtained from the electronic database searches $(n=4743)$ were screened based on their title and abstract ( Fig. 1 [25]). Based on this screening, 4401 papers were excluded and 342 were retained for full text reading. On reviewing the papers, $231(68 \%)$ were excluded. Most of the excluded articles concerned local decisionmaking processes (meso/micro level) $(n=134)$, primarily related to the personal choice of being vaccinated (especially by people who are targeted for vaccination). Other excluded articles $(n=83)$ did not concern policy-making but related to the influenza vaccines specifically, i.e. composition, virus strain selection (virology and immunology assays), vaccine efficacy/effectiveness (randomized clinical trials, economic evaluations and modelling), adverse events of vaccines and vaccination rates. Decisions solely regarding antiviral policy were also excluded $(\mathrm{n}=14)$.

\section{[FIG. 1. ]}

A total of 111 papers from primary and secondary sources met our inclusion criteria (Annex 3). We believe that both primary and secondary documents are important and complementary sources, although the latter are easier accessible as they are often published in scientific journals.

\section{RESULTS}

Two thirds of the papers included in our analysis $(n=76)$ were secondary documents that were written by research institutes or universities often indirectly involved in policy-making, and explained or discussed policy. One third of papers $(n=35)$ were primary documents, mainly from the health departments of national governments (esp. US, Canada and Australia) and international organizations (i.e.: WHO, ECDC) directly involved in policy-making. 
Silva, M.L., Perrier, L., Cohen, J.M., Paget, W.J., Mosnier, A., Späth, H.M. A literature review to identify factors that determine policies for influenza vaccination. Health Policy: 2015, 119(6), 697-708

\subsection{Description of the study populations}

Most of the studies ( $n=44,40 \%)$ evaluated the United States' (US) policies at the local, state, or federal levels. The US federal policy was compared to the Canadian, European, and Latin American policies in seven other studies. Eight of the studies were conducted in Canada and mainly evaluated their influenza pandemic preparedness plans and compared their national influenza vaccine strategies to other countries. Countries from the WHO European Region (France, Germany, Italy, Israel, and the Netherlands) published twelve studies; one of the studies was a comparison with the Canadian and US strategies.

Representing the eastern side of the globe, Australia $(n=7)$, India $(n=2)$ and Hong Kong $(n=1)$ evaluated their seasonal influenza vaccination strategy and pandemic preparedness plan. Twenty-nine of the studies $(26 \%)$ did not focus on a particular location for the analysis, instead making a global comparison about vaccination policies and influenza pandemic preparedness plans.

The following sections offer an overview of the segments of the influenza vaccination policy chain from various perspectives: during seasonal and pandemic contexts, among different levels of decision in various countries, describing the stakeholders involved, and comparing the information and factors influencing policymaking in these locations. In Table 1 we present our findings illustrating the main information and factors mentioned in the papers that have an impact on the decisionmaking process for influenza vaccination policy.

\section{[TABLE 1]}

\subsection{INFORMATION INFLUENCING DECISIONS AND OTHER FACTORS}

Fourteen categories of information and factors influencing the vaccination policymaking were developed and ranked according to the number of papers reporting them (Annex 2). We found that the variety of information and factors used in policymaking has increased over time. Scientific information related to the vaccine and disease, such as safety, efficacy/effectiveness, clinical trials, and epidemiological studies, have always been reported [26] and [27], but immunological, virological, and antigenic studies are a more recent phenomenon [28], [29] and [30]. Regarding economic studies, for example, cost-effectiveness analyses of influenza vaccination were first reported in the US in 1997 [27], and later in 2003 in the Netherlands, together with mathematical modelling [31]. Following the 2009 pandemic, the use of these studies, jointly risk and uncertainty assessments, were frequently reported in European countries, the US, and Canada [32], [33] and [34]. Table 1 summarizes the information and factors by segment of the policy chain and gives examples of countries that emphasised them as having a strong impact in the decision-making process of influenza vaccination policy.

The evidence used by policy-makers was often associated with adjectives like 'best', 'solid', or 'empirical' in both primary [35] and [36] and secondary documents [37], [38], [39] and [40]. Frequently, the type of evidence used was not explicitly stated; 
Silva, M.L., Perrier, L., Cohen, J.M., Paget, W.J., Mosnier, A., Späth, H.M. A literature review to identify factors that determine policies for influenza vaccination. Health Policy: 2015, 119(6), 697-708

instead, the term 'scientific evidence' was employed [41], [42] and [43]. The guidelines provided by international organisations, national governments, or advisory boards were often the source of references for scientific studies and used for comparison with the realities in other countries [44] and [45].

The advice from the advisory boards was based on a combination of scientific data and the opinions of those involved [33]. The acceptability of the advice provided by policy-makers was usually influenced by the national political-economic context, public opinion, and logistics of vaccine distribution and availability [46] and [47]. Especially after the last pandemic (2009), ethics and international pressure were prominent factors in deciding the resources allocated for vaccine adoption and target groups for vaccination [48], [49] and [50].

The use of information and the factors influencing policy-making are specific to each country and are a function of the interactions of the stakeholders involved. In the next section, we reveal our findings for each segment of the influenza vaccination policy chain.

\subsection{THE ROLE AND RELATIONSHIP OF THE STAKEHOLDERS}

In principle, the interactions among the stakeholders involved in the policy chain, located at the macro (international, supranational, and national organisations), meso (healthcare providers), and micro (consumers) levels, could be generalised for all countries included in the review. In Fig. 2, we propose a schematic illustration of these interactions across the levels for the actors, stakeholders, and consumers. This illustration is based on the data extracted from the papers and is a suggestion for a global overview of the information and factors that impact the decision-making process of the influenza vaccination policy chain (Table 1).

\section{[FIG. 2.]}

\subsubsection{Vaccination recommendations}

The selection of risk groups to target for influenza vaccinations was often done at the international and national levels. In between there was a supranational level, where institutions, such as the ECDC in Europe and the PAHO (Pan American Health Organization) in the Americas, gathered national data to produce general guidance for concerned countries (linked to the supranational institution). The WHO (international level) has also gathered intrinsic data from countries to produce global recommendations. At the national level, recommendations from both international and supranational levels were frequently used during decision-making. For example, since the WHO established the current goals for vaccination coverage (2003), nations have been encouraged to improve their vaccination rates, beginning with the increased purchasing and reimbursement of vaccines for target groups [51].

By contrast, pandemic actions often reflected seasonal recommendations. For instance, pregnant women, obese people, and healthcare workers were subsequently targeted more for vaccination after the 2009 pandemic [52]. In this case, international 
Silva, M.L., Perrier, L., Cohen, J.M., Paget, W.J., Mosnier, A., Späth, H.M. A literature review to identify factors that determine policies for influenza vaccination. Health Policy: 2015, 119(6), 697-708

policy-making also affected national choices: following the United States, some European countries (UK and Finland) targeted healthy children for vaccinations [53] and [54].

The selection of vaccines for the influenza vaccination program was also considered as part of the vaccination recommendations, which was mostly done at the national level. This selection directly involved the other segments of the policy chain: to be adopted, the vaccine depended on market authorisation ('vaccine license'), and once adopted, it had to be purchased and reimbursed ('vaccine funding').

The interactions between the stakeholders involved in the determination of vaccination recommendations within countries appeared to be similar; however, differences were observed according to the geographic size and influenza vaccination expertise of the locale. In larger countries, such as the US, Canada, and Australia, the communication between the federal government, states/provinces, and communities was crucial for the execution of recommendations, especially during pandemics [35], [38] and [46]. In Europe, the strength of the expert opinion, represented by national advisory committees, universities, and national research institutes, was important [28], [32], [36], [47], [55] and [56]. The influence of the WHO was remarkable in India [49] and [57] and Israel [39], where they seemed to seek expertise. A similar relationship was observed with the PAHO in Latin America [51].

\subsubsection{Vaccine composition}

Each year the WHO recommends the virus strains that should compose the future seasonal vaccine for the Northern and Southern Hemispheres. For almost 60 years, this decision was made in cooperation with the WHO Collaborating Centres, National Influenza Centres, and animal influenza networks, which provide antigenic and genetic information [58]. Surveillance networks around the globe and grouped by region (i.e. European Influenza Surveillance Network and CDCs) were also important stakeholders and information providers [58], [59], [60], [61] and [62]. While mathematical modelling and analyses of risk benefit and transmissibility were reported, they were considered less important [58], [59], [60], [61] and [62]. The WHO recommended the vaccine composition to manufacturers, who usually adopted the recommendations. However, other types of influenza vaccines could be produced depending on the manufacturers' interests. This process required a close relationship between the vaccine manufacturers and the WHO [30], [58], [61], [63], [64], $[65]$ and [66].

\subsubsection{Vaccine license}

The process of vaccine authorisation generally began with submission of the manufacturers' requirements to regulatory agencies. These agencies could be at the national level (e.g. US Food and Drug Administration [FDA] or Japanese Pharmaceuticals and Medical Devices Agency) or at a more global level (European Medicines Agency [EMA]) [67] and [68]. Each of these agencies has specific licensing requirements and regulations. The FDA clinical trials are an interesting example, as they are transferable to most European countries, providing an incentive 
Silva, M.L., Perrier, L., Cohen, J.M., Paget, W.J., Mosnier, A., Späth, H.M. A literature review to identify factors that determine policies for influenza vaccination. Health Policy: 2015, 119(6), 697-708

to license US vaccines for the European market; however, transfer from European countries to the US is impossible [67].

Surprisingly, we found that the procedures for licensing pandemic vaccines were similar to seasonal vaccines. Indeed, having a licensed seasonal vaccine influenced the licensing of a pandemic vaccine from the same manufacturer. For example, until recently, the FDA declared that a license for an adjuvanted pandemic vaccine could only be obtained if the manufacturer presented evidence of the clinical efficacy of a similarly adjuvanted seasonal influenza vaccine [68].

\subsubsection{Vaccine funding}

Actors in vaccination funding may be public or private and may belong to international or national organisations. At the international level (e.g. during last 2009 pandemic), the WHO has established a 'virtual international vaccine stockpile and advanced purchase mechanism' to secure resources to buy vaccines for developing countries [69]. At the national level, governments and healthcare providers represented the main purchasers for the public and private sector, respectively [70]. In the US, for example, the largest consumer of influenza vaccines was the federal government, with contracts established between the CDC and manufacturers for millions of doses each year [71]. However, the state and local health departments, pharmacies, and private healthcare providers (i.e. private general practitioners, nursing homes, and hospitals) were also purchasers of vaccines [71]. Likewise, in Australia, vaccine purchase was the responsibility of the Commonwealth government, who considered recommendations from experts, and was mostly financed by the state governments [72]. Similarly, in Latin America and Europe, vaccines offered through the public sector were purchased through governmental funds and available to the public free of charge [32], [51] and [52].

The reimbursement of vaccination costs to the patient or healthcare facilities, including hospitals, nursing homes, and medical offices, could be performed by public health departments at the national or local levels or by insurance companies, depending on the particular healthcare system of the country. In accordance with a paper by $\mathrm{Ng}$ et al. [52], we classified vaccine subsidies into three groups by country and found that: (1) $85 \%$ of countries provided vaccines without any charge to the recipient ('free'); (2) $6 \%$ of countries subsidised part of the vaccine and administration fee ('partial reimbursed'); and (3) 9\% of countries covered vaccines subsidies with national health insurance programs for specific risk groups ('insured').

During the last pandemic (2009), decisions regarding which vaccine to buy varied between countries. For instance, in Canada, as in Europe, the government and its advisors chose to purchase an adjuvanted vaccine, in contrast to the US and Australia [33] and [72]. Contracts were negotiated either by the national authorities with immediate effect or by certain prompts, such as the declaration of a phase 6 pandemic by the WHO [53].

Purchasing decisions regarding vaccine supply during seasonal influenza were commonly based on epidemiological data (trend predictions for the number of 
Silva, M.L., Perrier, L., Cohen, J.M., Paget, W.J., Mosnier, A., Späth, H.M. A literature review to identify factors that determine policies for influenza vaccination. Health Policy: 2015, 119(6), 697-708

contaminated people the following year) and demographic data (a possible increase in the elderly population) [53] and [66]. This information was generally provided by surveillance networks, virology laboratories, and national health institutes. By contrast, for pandemics, modelling had a greater impact [73], [74] and [75]. Furthermore, new factors influenced the decision because of the limited data regarding the clinical and epidemiological aspects of pandemics and the ethical and logistical challenges, including public acceptability [33]. The media attention was also considerably higher during the 2009 pandemic, which was likely triggered by official declarations regarding the morbidity and mortality, for example [53]. There was a high level of uncertainty regarding the severity and potential time course of a pandemic when decisions on vaccine purchases had to be made [53].

\section{DISCUSSION}

\subsection{Limitations}

Our study design and review strategy allowed investigation of a variety of segments of the influenza vaccination policy chain over a long period (1994-2012). This enabled exploration of the different interactions among policy-makers in several countries. Indeed, this review provides a broad outline of the literature in this field. However, there are some limitations to this study.

Our analysis was mainly based on secondary documents, which are often published by researchers who are indirectly involved in the policy-making process. These documents may not necessarily represent the reality of the process, but the opinions of researchers. However, these researchers may also have a holistic perspective that the experts directly involved in the policy-making may not have. Therefore, we believe that, based on the objectives of our review, these researchers' opinions are relevant and complementary to the primary documents. The primary documents, which are considered the most reliable source of information, comprised only one third of papers analysed. This is most likely due to the fact that they were not published in the databases we searched, or simply not published anywhere, hindering public access. Hence, we believe that analysing both primary and secondary documents provides insight into the development of specific statements and a general perspective of the policy-making process, respectively.

The databases we searched were selected in order to retrieve the largest number of documents pertinent to our objectives. Google Scholar together with other conventional literature retrieval tools were selected instead of extremely broad search engines (i.e.: Google) to improve the relevance of documents and to reduce the time needed to sort through the results [76]. However, this choice may have resulted in missing some relevant data. For example, documents published by the National Influenza Vaccine Summit on the CDC website were not found, although two of the articles that we analysed referred to its key role in influenza policy in the USA [44] and [77]. The choice of database could have generated bias in the inclusion of important documents, but also the application of the inclusion criteria and further checklist for full-text reading, may have contributed to that bias. 
Silva, M.L., Perrier, L., Cohen, J.M., Paget, W.J., Mosnier, A., Späth, H.M. A literature review to identify factors that determine policies for influenza vaccination. Health Policy: 2015, 119(6), 697-708

We observed an over-representation of studies conducted in the US. This might be related to the fact that the US government is responsible for buying and distributing influenza vaccines in the US, work that is largely carried out by the CDC. As a result, there are many US publications in the public domain regarding this issue, which appear every year. For example, the CDC gives a regular update on vaccine supplies each winter. This situation is not comparable to other countries, where other procedures are used and supply is often derived from the private market.

Studies we did examine were unclear on their geographical position, and varied in their grade of suitable descriptions of the policy-making process, role and relationship between the stakeholders involved, information used, and various other factors that influenced the policy-making process. We found that the relationship between the actors and institutions within countries and among different levels of decision-making were under-reported (i.e.: public institutes and vaccine manufacturers), especially during seasonal influenza outbreaks. Furthermore, because there was a peak in publications after the last pandemic human influenza (A(H1N1)pdm09), our findings could have been influenced by an overrepresentation of pandemic policy-making, consequently under-reporting seasonal influenza policy-making.

In addition to the global over/under-declaration of certain policy-making determinants, we also observed that each of the documents analysed emphasised different information and factors influencing vaccination policy. For example, authors investigating policy-making during annual epidemics rarely mentioned the possible influence of the media and anti-vaccination actions [53]. In contrast, we observed over-declarations of how evidence was used, emphasised by adjectives such as "best" or "solid" [35], [36], [37], [38], [39] and [40]. Moreover, primary documents were more likely to highlight the uncertainty of the process [46], [59] and [78], whereas secondary documents were more likely to mention the influence of experts opinions and ethical issues [33] and [42].

For all these reasons, care should be taken when comparing these studies because of the differences in the methodologies and context in which they were studied. Most of the studies evaluated policy-making during pandemics, providing detailed, real-time information about the measures applied; however, these suffered from a limited perspective. Other pandemic studies used retrospective document analysis, providing larger overview of the whole process but with less detailed information. Pandemic studies generally investigated the implementation of policies, often neglecting the role of the stakeholders, relationships, and information used. The few studies that provided surveys, interviews, and workshops with the stakeholders aided in the understanding of their interactions and attitudes towards the information used and influencing factors. These techniques have not been used during seasonal influenza outside of the US and Australia.

Despite the large number of studies included in this review, most reports were only concerned with one segment of the policy chain: vaccination recommendations. The number of studies providing a holistic picture of the entire policy chain was a minimum. For future studies, we believe that a general overview of the policy chain 
Silva, M.L., Perrier, L., Cohen, J.M., Paget, W.J., Mosnier, A., Späth, H.M. A literature review to identify factors that determine policies for influenza vaccination. Health Policy: 2015, 119(6), 697-708

would help policy-makers and stakeholders to improve their performance in this process (Fig. 2).

\subsection{Information influencing decisions and other impacting factors}

Clinical and epidemiological studies were the most relevant data used by several actors in each segment of the policy chain. In general, the type of information used in both influenza contexts was similar, but a wider variety was reported in studies exploring the pandemic context. We hypothesise that the concepts of uncertainty, risk management, and emergency actions were usually adopted because of the risk faced by the policy-makers. For instance, during pandemics, budget and logistical factors (vaccine availability and distribution) were of main importance when deciding which vaccines to purchase. In the same context, experts' opinions, outside of the circuit of actors and stakeholders, had a higher impact in pandemics than in annual epidemics, where target groups were selected for vaccination recommendations. We found that the routine annual influenza policy became an uncertainty in the context of risk management when a pandemic was declared.

In the European Union, the response strategy for the last pandemic influenza was coordinated by the Health Security Committee (HSC), with the collaboration of the ECDC and the EMA. Member states considered the HSC a 'useful platform for public health risk management and risk communication as well as for coordinating at EU level the response' [79]. In addition, those European organisations had agreed that it was important that 'those being offered the vaccines had [been] given clear guidance and information on the likelihood of them being affected by the virus and of experiencing severe outcomes to enable them to make informed choices' [59]. However, the interactions between these organisations and the national governments were weak, resulting in a communication failure with the physicians and general public. A communication failure was also observed among the regulatory authorities and vaccine manufacturers. In the US, Macher and Springs remarked there was 'insufficient written guidance and consultation with manufacturers available on the licensure requirements for new influenza vaccines using alternative technologies' [80]. This lack of communication, allied with the possible limited expertise of the regulatory authorities on testing new products, could hinder manufacturers' incentives and $R \& D$ efforts related to alternative influenza virus vaccine technologies. Additionally, the entire research, development, and approval process can require 10 years or more, costing approximately US \$110-802 million [81]. For pandemic vaccines, at least 20 weeks are required from the time the pandemic virus is identified until the first vaccine doses become available [82].

Interestingly, some information, such as mathematical modelling and ethical issues, were often reported but appeared to be underused [58], [59], [60], [61] and [62]. As previously mentioned, this could be because the information used and factors that influenced policies were underreported. However, during 2009 pandemic we observed a clear impact of mathematical modelling and other new factors of influence, such as the limited data regarding clinical and epidemiological aspects, and ethical and logistical challenges including public acceptability (which was also an important factor influencing purchase during seasonal influenza) [33]. A lack of 
Silva, M.L., Perrier, L., Cohen, J.M., Paget, W.J., Mosnier, A., Späth, H.M. A literature review to identify factors that determine policies for influenza vaccination. Health Policy: 2015, 119(6), 697-708

data was reported as a crucial limiting factor for a robust policy-making process, especially during pandemics when decisions must be made faster than during seasonal influenza. From an economic perspective, we observed that costeffectiveness evidence was often required but not significantly taken into account. As presented by Drummond et al., we believe that the political visibility and budgetary impact of introducing a new vaccination programme is higher than simply reimbursement approval of a new, standard, pharmaceutical product. Furthermore, in most countries, there was a lack of communication between the authorities responsible for vaccine licensing and those for other health technologies, and different criteria may apply [83].

A scarcity of resources and other issues incited providers (national influenza programs and healthcare insurance) to prioritise some groups for receiving influenza vaccine for free or with reimbursement. The 'best' or 'optimal' strategy for including or excluding certain groups for vaccine prioritisation has not yet been fully clarified [52]. We observed that after the last pandemic, policy-makers and their advisors were worried about presenting the clinical and epidemiological evidence used and how the advice was established. Establishing the advice is a key step in the decision process, as this advice is commonly used to justify the actions taken by policymakers. It is therefore important to understand how this advice is created. However, public access to meetings is still difficult, especially in Europe. The US has largely improved the transparency of their decision-making process by making meeting transcripts publicly available through official websites.

We suggest that efforts should be made to facilitate better communication between the stakeholders involved in the policy chain. This collaboration will produce more robust information and provide transparency in the evidence used in the decisionmaking process [84]. Additionally, communication with people concerned about vaccination should be enhanced with the goal of improving funding and reimbursement for both providers and patients [11] and [81]. Indeed, vaccination recommendations alone were insufficient in improving vaccination rates in various countries, regardless of their development status [11] and [81]. However, recommendations are still a crucial tool for boosting vaccine use [11]. In France, for example, vaccine reimbursement was placed under the following restriction: a vaccine not recommended by health authorities was never reimbursed, whereas a recommended vaccine was theoretically reimbursed [85].

\subsection{Role and relationship of the stakeholders as determinants of policy-making}

The actors, institutes, and stakeholders, who are involved in the influenza policymaking chain at different levels, have complex interactions. Although it was difficult to categorise all of the stakeholders involved in the policy-making process, their relationships, and their respective segments in the policy chain into one scheme, we have amalgamated these data and provided a holistic overview, shown in Fig. 2. To the best of our knowledge, there is no similar scheme found in the literature.

Studies that reported on seasonal influenza, which differ from pandemic studies, provided worse explanations of the interactions between the stakeholders; possibly 
Silva, M.L., Perrier, L., Cohen, J.M., Paget, W.J., Mosnier, A., Späth, H.M. A literature review to identify factors that determine policies for influenza vaccination. Health Policy: 2015, 119(6), 697-708

because routine procedures hide the importance of a clear definition of the stakeholders' role in the process and the impact of their relationship on the use of information. We found that the internal relationships among the institutes at the national level were not well described in the literature. However, their interactions with organisations at the international level and the latter with vaccine manufacturers were better reported.

As the international authority for health within the United Nations, the WHO successfully adopted responsibility for providing global guidance on influenza vaccine recommendations. The composition of vaccines is assessed yearly through an exchange of information, technology and communication among experts. However, their relationship with vaccine manufacturers may be strained during a pandemic. For example, during pre-pandemic preparation in 2007, the Indonesian government and the WHO failed to resolve the virus-sharing issue with manufacturers who 'developed, and patented, influenza vaccines that the Indonesian authorities could not purchase' [86]. This was considered a "breakdown of trust" in the global influenza surveillance network [87].

Another example of the relationship between the WHO and vaccine manufacturers acting as main stakeholders is the effort to develop a 'universal vaccine'. This promising vaccine, if it addresses the issue of seasonal variations in the influenza virus, could dramatically influence immunisation policies in the future [88]. Indeed, new formulations for the vaccine have been proposed. Responding to vaccines recently licensed in the US (2012) and Europe (2013) that contain four strains of the virus, the WHO has started to recommend strain compositions for quadrivalent vaccines, along with the previous trivalent vaccines, since the 2013-14 influenza season. At present, no evidence of any incremental clinical benefit for quadrivalent over trivalent vaccines has been shown [89], though we think that quadrivalent vaccines represent a step in the progression of vaccine development.

There are currently only a few influenza vaccine manufacturers, and only three of these have recently proposed new technologies, such as quadrivalent vaccine composition and nasal administration [80]. Interestingly, 70\% of vaccine production occurs in North America, Europe (France and the UK), Australia, and Japan [86] and [90]. This could cause a problem for the vaccine supply. However, there is an active interaction between the WHO and industrialised countries, manufacturers, and the entire international community to promote global solidarity and collaboration. The low number of manufacturers, which could subsequently lead to a disruption in the vaccine supply, might be a result of the high cost of vaccine production technology and numerous regulatory requirements, mentioned earlier.

We observed that vaccine manufacturers and the WHO have a close relationship, which is necessary for efficient responses to influenza outbreaks. However, occasionally, especially during times of uncertainty (pandemic), this relationship transparency became weak and raised suspicions that there were conflicts of interest in the decisions made. We propose strengthening the transparency of these interactions, for example by making the minutes or transcriptions of policy meetings available to the public domain. 
Silva, M.L., Perrier, L., Cohen, J.M., Paget, W.J., Mosnier, A., Späth, H.M. A literature review to identify factors that determine policies for influenza vaccination. Health Policy: 2015, 119(6), 697-708

\section{CONCLUSIONS}

This review has highlighted two important findings. First, the most relevant evidence for influenza policy-making remains clinical and epidemiological studies, although mathematical modelling and ethical issues have acquired greater importance since the last pandemic. Indeed, recommendations in response to the 2009 pandemic triggered changes in seasonal influenza policies in later years. Though political issues, together with international pressure, were rarely mentioned as a justification, they nevertheless seemed to be influential in seasonal and pandemic influenza national policies.

Second, the interactions between the stakeholders in the influenza vaccination policy chain may change according to whether one is dealing with seasonal or pandemic influenza. These complex interactions should be considered one of the determinants of the policy-making process. A notable example is the unsuccessful pandemic policy of 2009, which can be attributed to communication failures, especially with the physicians and general public. The role and relationship of the stakeholders, including the actors at different levels and vaccine manufacturers, remains unclear, especially during seasonal influenza. Nevertheless, as a result of improved transparency, national governments and the WHO increasingly provide declarations of interest of the actors involved and also emphasise the use of evidence in policymaking (this development is particularly clear after the last pandemic).

Generally, our global literature review could not define precise interactions or detailed use of evidence because of the complexity and numerous factors that influenced the decision-making process. Therefore, we recommend that further work should be carried out at a national level for only a few countries, using qualitative exploratory methods that would enable a holistic perspective and a better assessment of the stakeholder viewpoints and interactions. In addition, this approach will reduce the declaration bias regarding the analysis of policy-making processes and especially policy-making determinants.

\section{Competing interests}

The authors declare that they have no competing interests.

\section{Authors' contributions}

HMS designed the systematic search strategy. MLS and HMS extracted data from the papers. MLS, HMS, LP, JP, and AM participated in the data analysis. MLS, LP, JMC, JP, AM, and HMS prepared the manuscript. All authors read and approved the final manuscript.

\section{Acknowledgments}

MLS received a doctoral scholarship from the Science without Borders program, primarily funded by the Brazilian Federal Government. The authors would like to thank the referees for their insightful comments and suggestions. The authors would 
Silva, M.L., Perrier, L., Cohen, J.M., Paget, W.J., Mosnier, A., Späth, H.M. A literature review to identify factors that determine policies for influenza vaccination. Health Policy: 2015, 119(6), 697-708

also like to thank Douglas Fleming, of the Royal College of General Practitioners Research \& Surveillance Centre (Birmingham, UK), and Valérie Buthion, of the COACTIS EA 4161, University of Lyon, ISH (Lyon, FR), for their assistance and support. Sophie Domingues-Montanari helped with the final editing of the manuscript.

\section{[APPENDIX A]}

\section{REFERENCES}

[1] A.S. Monto, F. Ansaldi, R. Aspinall, J.E. McElhaney, L.F. Montano, K.L. Nichol, et al. Influenza control in the 21st century: optimizing protection of older adults Vaccine, 27 (2009), pp. 5043-5053

[2]M.L. Silva, L. Perrier, H.-M. Späth, I. Grog, A. Mosnier, N. Havet, et al.Economic burden of seasonal influenza B in France during winter 2010-2011BMC Public Health, 14 (2014), p. 56 http://dx.doi.org.proxy.library.uu.nl/10.1186/1471-2458-14-56

[3] T.M. Bailey, C. Haines, R.J. Rosychuk, T.J. Marrie, O. Yonge, R. Lake, et al. Public engagement on ethical principles in allocating scarce resources during an influenza pandemic Vaccine, 29 (2011), pp. 3111-3117

[4]J. Wallinga, M. van Boven, M. Lipsitch Optimizing infectious disease interventions during an emerging epidemic Proceedings of the National Academy of Sciences of the United States of America, 107 (2010), pp. 923-928

[5]L.C. Rosella, K. Wilson, N.S. Crowcroft, A. Chu, R. Upshur, D. Willison, et al. Pandemic H1N1 in Canada and the use of evidence in developing public health policies-a policy analysis Social Science and Medicine, 83 (2013), pp. 1-9

http://dx.doi.org.proxy.library.uu.nl/10.1016/j.socscimed.2013.02.009 (1982)

[6] T. Timpka, H. Eriksson, E.A. Gursky, J.M. Nyce, M. Morin, J. Jenvald, et al. Populationbased simulations of influenza pandemics: validity and significance for public health policy Bulletin of the World Health Organization, 87 (2009), pp. 305-311

[7] L. Barnitz, M. Berkwits The health care response to pandemic influenza Annals of Internal Medicine, 145 (2006), pp. 135-137

[8] M. Bryson, P. Duclos, A. Jolly, J. Bryson A systematic review of national immunization policy making processes Vaccine, 28 (Suppl 1) (2010), pp. A6-A12

[9] P. Duclos, S. Ortynsky, N. Abeysinghe, N. Cakmak, C.B. Janusz, B. Jauregui, et al. Monitoring of progress in the establishment and strengthening of national immunization technical advisory groups Vaccine, 30 (2012), pp. 7147-7152

[10] WHO World Health Organization: fact sheet seasonal influenza (Fact sheet No. 211), WHO Influenza Seas WHO (2009)

[11] A. Palache Seasonal influenza vaccine provision in 157 countries (2004-2009) and the potential influence of national public health policies Vaccine, 29 (2011), pp. 9459-9466

[12] E. Miller Report from the SAGE working group on influenza vaccines and immunizations (2011)

[13] W.E.P. Beyer, J. McElhaney, D.J. Smith, A.S. Monto, J.S. Nguyen-Van-Tam, A.D.M.E. Osterhaus Cochrane re-arranged: support for policies to vaccinate elderly people against influenza Vaccine, 31 (2013), pp. 6030-6033

[14] T. Jefferson, C. Di Pietrantonj, L.A. Al-Ansary, E. Ferroni, S. Thorning, R.E. Thomas Vaccines for preventing influenza in the elderly (review) Cochrane Database Syst. Rev. (February (2)) (2010), p. CD004876

[15] J.A. Knottnerus Influenza vaccination in the elderly: current evidence and uncertainties Journal of Clinical Epidemiology, 62 (2009), pp. 675-676

[16] J. Gatwood, M.I. Meltzer, M. Messonnier, I.R. Ortega-Sanchez, R. Balkrishnan, L.A. Prosser Seasonal influenza vaccination of healthy working-age adults a review of economic evaluations Drugs, 72 (2012), pp. 35-48

[17] J.R. Ortiz, J.A. Englund, K.M. Neuzil Influenza vaccine for pregnant women in resourceconstrained countries: a review of the evidence to inform policy decisions Vaccine, 29 (2011), pp. 4439-4452 
Silva, M.L., Perrier, L., Cohen, J.M., Paget, W.J., Mosnier, A., Späth, H.M. A literature review to identify factors that determine policies for influenza vaccination. Health Policy: 2015, 119(6), 697-708

[18] C.R. Beck, B.C. McKenzie, A.B. Hashim, R.C. Harris, A. Zanuzdana, G. Agboado, et al. Influenza vaccination for immunocompromised patients: systematic review and metaanalysis from a public health policy perspective PLoS ONE, 6 (2011)

[19] J. Cawley, H.F. Hull, M.D. Rousculp Strategies for implementing school-located influenza vaccination of children: a systematic literature review Journal of School Health, 80 (2010), pp. 167-175 http://dx.doi.org.proxy.library.uu.nl/10.1111/j. 17461561.2009.00482.x

[20] A.T. Newall, H. Kelly, S. Harsley, P.A. Scuffham Cost effectiveness of influenza vaccination in older adults: a critical review of economic evaluations for the 50- to 64-year age group Pharmacoeconomics, 27 (2009), pp. 439-450

[21] A. Burls, R. Jordan, P. Barton, B. Olowokure, B. Wake, E. Albon, et al. Vaccinating healthcare workers against influenza to protect the vulnerable-is it a good use of healthcare resources? A systematic review of the evidence and an economic evaluation

Vaccine, 24 (2006), pp. 4212-4221

[22] E.J. Luna, V.L. Gattas Effectiveness of the Brazilian influenza vaccination policy, a systematic review Revista do Instituto de Medicina Tropical de São Paulo, 52 (2010), pp. 175-181

[23] D. Turner, A. Wailoo, K. Nicholson, N. Cooper, A. Sutton, K. Abrams Systematic review and economic decision modelling for the prevention and treatment of influenza $A$ and $B$ Health Technology Assessment, 7 (2003), pp. 1-170 (iii-iv, xi-xiii)

[24] A.L. Ottenberg, J.T. Wu, G.A. Poland, R.M. Jacobson, B.A. Koenig, J.C. Tilburt Vaccinating health care workers against influenza: the ethical and legal rationale for a mandate American Journal of Public Health, 101 (2011), pp. 212-216

[25] D. Moher, A. Liberati, J. Tetzlaff, D.G. Altman Preferred reporting items for systematic reviews and meta-analyses: the PRISMA statement Annals of Internal Medicine, 151 (2009), pp. 264-269 http://dx.doi.org.proxy.library.uu.nl/10.7326/0003-4819-151-4200908180-00135

[26] S.E. Tamblyn Pandemic planning in Canada European Journal of Epidemiology, 10 (1994), pp. 503-505

[27] A.R. Hinman Quantitative policy analysis and public health policy: a macro and a micro view American Journal of Preventive Medicine, 13 (1997), pp. 6-11

[28] R. Fock, H. Bergmann, H. Bussmann, G. Fell, E.J. Finke, U. Koch, et al. Conceptional considerations for a German influenza pandemic preparedness plan Medical Microbiology and Immunology (Berlin)., 191 (2002), pp. 191-195

[29] K.F. Gensheimer, K. Fukuda, L. Brammer, N. Cox, P.A. Patriarca, R.A. Strikes

Preparing for pandemic influenza: the need for enhanced surveillance Vaccine, 20 (Suppl 2) (2002), pp. S63-S65

[30] D.S. Fedson Preparing for pandemic vaccination: an international policy agenda for vaccine development Journal of Public Health Policy, 26 (2005), pp. 4-29

[31] M.L.L. van Genugten, M.-L.A. Heijnen, J.C. Jager Pandemic influenza and healthcare demand in the Netherlands: scenario analysis Emerging Infectious Diseases, 9 (2003), pp. 531-538

[32] M.T. Labro, J. Etiemble The strategy against influenza Revue du Praticien, 60 (2010), pp. 81-92

[33] S.M. Moghadas, N.J. Pizzi, J.H. Wu, S.E. Tamblyn, D.N. Fisman Canada in the face of the 2009 H1N1 pandemic Influenza and Other Respiratory Viruses, 5 (2011), pp. 83-88

[34] R. Maciejewski, P. Livengood, S. Rudolph, T.F. Collins, D.S. Ebert, R.T. Brigantic, et al. A pandemic influenza modeling and visualization tool Journal of Visual Languages and Computing (2011)

[35] R. Kort, A.J. Stuart, E. Bontovics Ensuring a broad and inclusive approach: a provincial perspective on pandemic preparedness Canadian Journal of Public Health/Revue Canadienne de Sante Publique, 96 (2005), pp. 409-411

[36] A. Nicoll, A. Ammon, A. Amato, B. Ciancio, P. Zucs, I. Devaux, et al. Experience and lessons from surveillance and studies of the 2009 pandemic in Europe Public Health, 124 (2010), pp. 14-23

[37] J. Leask, C.M. Helms, M.Y. Chow, S.C. Robbins, P.B. Mclntyre Making influenza vaccination mandatory for health care workers: the views of NSW Health administrators and clinical leaders Northwest Public Health Bulletin, 21 (2010), pp. 243-247 
Silva, M.L., Perrier, L., Cohen, J.M., Paget, W.J., Mosnier, A., Späth, H.M. A literature review to identify factors that determine policies for influenza vaccination. Health Policy: 2015, 119(6), 697-708

[38] A. Torda Ethical issues in pandemic planning Medical Journal of Australia, 185 (2006), pp. S73-S76

[39] H. Levine, R.D. Balicer, D. Laor, I. Grotto Challenges and opportunities in the Israeli 2009 pandemic influenza vaccination program Human Vaccines, 7 (2011), pp. 1077-1082

[40] J. Kotalik Preparing for an influenza pandemic: ethical issues Bioethics, 19 (2005), pp. 422-431

[41] D. Rosner Spanish flu, or whatever it is...: the paradox of public health in a time of crisis Public Health Reports, 125 (2010), pp. 38-47

[42] K. Kinlaw, D.H. Barrett, R.J. Levine Ethical guidelines in pandemic influenza: recommendations of the Ethics Subcommittee of the Advisory Committee of the Director, Centers for Disease Control and Prevention Disaster Medicine and Public Health PreparednessV 3 (Suppl 2) (2009), pp. S185-S192

[43] G. Dehner WHO knows best? National and international responses to pandemic threats and the lessons of 1976 Journal of the History of Medicine and Allied Sciences, 65 (2010), pp. $478-513$

[44] P.P. Berman, W.A. Orenstein, A.R. Hinman, J. Gazmararian Stakeholder attitudes toward influenza vaccination policy in the United States Health Promotion Practice, 11 (2010), pp. 807-816

[45] J. Mereckiene, S. Cotter, F. D’Ancona, C. Giambi, A. Nicoll, D. Levy-Bruhl, et al.

Differences in national influenza vaccination policies across the European Union, Norway and Iceland 2008-2009

Eurosurveillance, 15 (44) (2010)

[46] K.K. Lewis The pandemic threat: are we prepared? Issue Brief Mass Health Policy Forum (2006), pp. 1-14

[47] S. Esposito, N. Principi Differences in vaccinations in European Union Human Vaccines, 4 (2008), pp. 313-315

[48] D.J. Barnett, H.A. Taylor, J.G. Hodge, J.M. Links

Resource allocation on the frontlines of public health preparedness and response: report of a summit on legal and ethical issues

Public Health Reports, 124 (2009), pp. 295-303

[49] M. Kakkar, S. Hazarika, S. Zodpey, K.S. Reddy Influenza pandemic preparedness and response: a review of legal frameworks in India Indian Journal of Public Health, 54 (2010), pp. $11-17$

[50] P.E. French Enhancing the legitimacy of local government pandemic influenza planning through transparency and public engagement Public Administration Review, 71 (2011), pp. 253-264

[51] A.M. Ropero-Alvarez, H.J. Kurtis, M.C. Danovaro-Holliday, C. Ruiz-Matus, J.K. Andrus Expansion of seasonal influenza vaccination in the Americas BMC Public Health, 9 (2009), p. 361

[52] S. Ng, P. Wu, H. Nishiura, D.K. Ip, E.S. Lee, B.J. Cowling An analysis of national target groups for monovalent 2009 pandemic influenza vaccine and trivalent seasonal influenza vaccines in 2009-10 and 2010-11 BMC Infectious Diseases, 11 (2011), p. 230

[53] A.S. Monto Seasonal influenza and vaccination coverage Vaccine, 28 (Suppl 4) (2010), pp. D33-D44

[54] M. Granstrom, A.C. Voordouw Registration of influenza vaccines for children in Europe Vaccine, 29 (2011), pp. 7572-7575

[55] M. Ajelli, S. Merler, A. Pugliese, C. Rizzo Model predictions and evaluation of possible control strategies for the $2009 \mathrm{~A} / \mathrm{H} 1 \mathrm{~N} 1 \mathrm{v}$ influenza pandemic in Italy Epidemiology \& Infection, 139 (2011), pp. 68-79

[56] J. Mereckiene, S. Cotter, T. Weber, A. Nicoll, F. D'Ancona, P. Lopalco, et al. Influenza A(H1N1)pdm09 vaccination policies and coverage in Europe Eurosurveillance, 17 (2012), pp. $18-27$

[57] R. Chawla, R.K. Sharma, J.R. Bhardwaj Influenza a (H1N1) outbreak and challenges for pharmacotherapy Indian Journal of Physiology and Pharmacology, 53 (2009), pp. 113-126

[58] W.K. Ampofo, N. Baylor, S. Cobey, N.J. Cox, S. Daves, S. Edwards, et al. Improving influenza vaccine virus selection report of a WHO informal consultation held at WHO headquarters, Geneva, Switzerland, 14-16 June 2010 Influenza and Other Respiratory Viruses, 6 (2012), pp. 142-150 
Silva, M.L., Perrier, L., Cohen, J.M., Paget, W.J., Mosnier, A., Späth, H.M. A literature review to identify factors that determine policies for influenza vaccination. Health Policy: 2015, 119(6), 697-708

[59] K. Johansen, A. Nicoll, B.C. Ciancio, P. Kramarz Pandemic influenza a(H1n1) 2009 vaccines in the European Union Eurosurveillance, 14 (2009), pp. 12-18

[60] E. O'Neill, R.O. Donis Generation and characterization of candidate vaccine viruses for prepandemic influenza vaccines Current Topics in Microbiology and Immunology, 333 (2009), pp. 83-108

[61] S.H. Cho The optimal composition of influenza vaccines subject to random production yields Manufacturing \& Service Operations Management, 12 (2010), pp. 256-277

[62] J.T. Wu, L.M. Wein, A.S. Perelson Optimization of influenza vaccine selection Operations Research, 53 (2005), pp. 456-476

[63] A. Kamradt-Scott Changing perceptions of pandemic influenza and public health responses American Journal of Public Health, 102 (2012), pp. 90-98

[64] M. Friede, I. Serdobova, L. Palkonyay, M.P. Kieny Technology transfer hub for pandemic influenza vaccine Vaccine, 27 (2009), pp. 631-632

[65] W. Wunderli, S. Chappuis, H. Wunderli World-wide surveillance of influenza Sozial-und Praventivmedizin, 42 (Suppl 2) (1997), pp. S83-S87

[66] W.A. Orenstein, W. Schaffner Lessons learned: role of influenza vaccine production, distribution, supply, and demand - what it means for the provider American Journal of Medicine, 121 (2008), pp. S22-S27

[67] G.K. Gronvall, L.L. Borio Removing barriers to global pandemic influenza vaccination Biosecurity and Bioterrorism, 4 (2006), pp. 168-175

[68] D.S. Fedson Vaccine development for an imminent pandemic-why we should worry, what must we do Human Vaccines, 2 (2006), pp. 38-42

[69] WHO WHO and international community make progress towards ensuring access of developing countries, WHO Media Cent WHO (2007) pii: 19700. Available online: http://www.eurosurveillance.org. proxy.library.uu.nI/ViewArticle.aspx?Articleld=19700

[70] A. Nevel, C. Layton Influenza vaccine who buys it and who sells it (2005) http://www.rti.org/pubs/laytonwhobuysit.pdf $\rangle$ (accessed February 22, 2014)

[71] J.G. Hodge, J.P. O'Connell The legal environment underlying influenza vaccine allocation and distribution strategies Journal of Public Health Management and Practice, 12 (2006), pp. 340-348

[72] T.S. Weeramanthri, A.G. Robertson, G.K. Dowse, P.V. Effler, M.G. Leclercq, J.D. Burtenshaw, et al. Response to pandemic (H1N1) 2009 influenza in Australia-lessons from a state health department perspective Australian Health Review, 34 (2010), pp. 477486

[73] A. Abelin, T. Colegate, S. Gardner, N. Hehme, A. Palache Lessons from pandemic influenza $A(H 1 N 1)$ : the research-based vaccine industry's perspective Vaccine, 29 (2011), pp. $1135-1138$

[74] T.D. Hollingsworth, D. Klinkenberg, H. Heesterbeek, R.M. Anderson Mitigation strategies for pandemic influenza A: balancing conflicting policy objectives PLoS Computational Biology, 7 (2011), p. e1001076

[75] K.J. Rambhia, M. Watson, T.K. Sell, R. Waldhorn, E. Toner Mass vaccination for the 2009 H1N1 pandemic: approaches, challenges, and recommendations Biosecurity and Bioterrorism, 8 (2010), pp. 321-330

[76] M. Boeker, W. Vach, E. Motschall Google scholar as replacement for systematic literature searches: good relative recall and precision are not enough BMC Medical Research Methodology, 13 (2013), p. 131 http://dx.doi.org.proxy.library.uu.nl/10.1186/1471-2288-13-131

[77] J.S. Ringel, M. Moore, J. Zambrano, N. Lurie Will routine annual influenza prevention and control systems serve the United States well in a pandemic? Disaster Medicine and Public Health Preparedness, 3 (Suppl 2) (2009), pp. S160-S165 http://dx.doi.org.proxy.library.uu.nl/10.1097/DMP.0b013e3181ad1833

[78] T. Tam, J. Sciberras, B. Mullington, A. King Fortune favours the prepared mind - A national perspective on pandemic preparedness Canadian Journal of Public Health/Revue Canadienne de Sante Publique, 96 (2005), pp. 406-408

[79] H. European Union Health Security Committee, E. Early Warning and Response System Report of the stakeholder consultation on health security in the European Union European Commission Health and Consumers Directorate-General, Brussels (2011) 
Silva, M.L., Perrier, L., Cohen, J.M., Paget, W.J., Mosnier, A., Späth, H.M. A literature review to identify factors that determine policies for influenza vaccination. Health Policy: 2015, 119(6), 697-708

http://ec.europa.eu.proxy.library.uu.nl/health/preparedness_response/docs/healthsecurity_r eport_en.pdf $\rangle$

[80] J.T. Macher, S.L. Springs Unhealthy technological investment: survey results and policy implications from influenza virus vaccine manufacturers (2013)

[81] J.M. Muzumdar, R.R. Cline Vaccine supply, demand, and policy: a primer Journal of American Pharmacists Association, 49 (2009), pp. 87-99

[82] B. Schwartz, W.A. Orenstein Prioritization of pandemic influenza vaccine: rationale and strategy for decision making Current Topics in Microbiology and Immunology, 333 (2009), pp. 495-507 http://dx.doi.org.proxy.library.uu.nl/10.1007/978-3-540-92165-3_24

[83] M. Drummond, C. Chevat, M. Lothgren Do we fully understand the economic value of vaccines?

Vaccine, 25 (2007), pp. 5945-5957

http://dx.doi.org.proxy.library.uu.nl/10.1016/j.vaccine.2007.04.070

[84] J.A. Gazmararian, W.A. Orenstein, P. Wortley, J.W. Buehler, L. Elon, J.P. Koplan, et al. Preventing influenza: vaccine systems and practices in the southeast Public Health Reports, 121 (2006), pp. 684-694

[85] D. Floret Vaccinations: élaboration des recommandations et de leur évolution en France Annales Pharmaceutiques Françaises, 67 (2009), pp. 219-223

http://dx.doi.org.proxy.library.uu.nl/10.1016/j.pharma.2009.03.006

[86] A. Kamradt-Scott, K. LeeThe 2011 pandemic influenza preparedness framework: global health secured or a missed opportunity?Political Studies, 59 (2011), pp. 831-847

[87] R. Ross CIDRAP News Indonesia details reasons for withholding H5N1 viruses CIDRAP (2008) 〈http://www.cidrap.umn.edu/news-perspective/2008/07/indonesia-detailsreasons-withholding-h5n1-viruses〉 (accessed October 10, 2014)

[88] D.M. Morens, J.K. Taubenberger, G.K. Folkers, A.S. Fauci Pandemic Influenza's 500th anniversary Clinical Infectious Diseases, 51 (2010), pp. 1442-1444

[89] R.B. Belshe The need for quadrivalent vaccine against seasonal influenza Vaccine, 28 (Suppl 4) (2010), pp. D45-D53

[90] N. Collin, S. Briand Influenza vaccine: globalization of public health stakes

Medecine Tropicale (Marseilles), 69 (2009), p. 322

\section{TABLES AND FIGURES}


Silva, M.L., Perrier, L., Cohen, J.M., Paget, W.J., Mosnier, A., Späth, H.M. A literature review to identify factors that determine policies for influenza vaccination. Health Policy: 2015, 119(6), 697-708
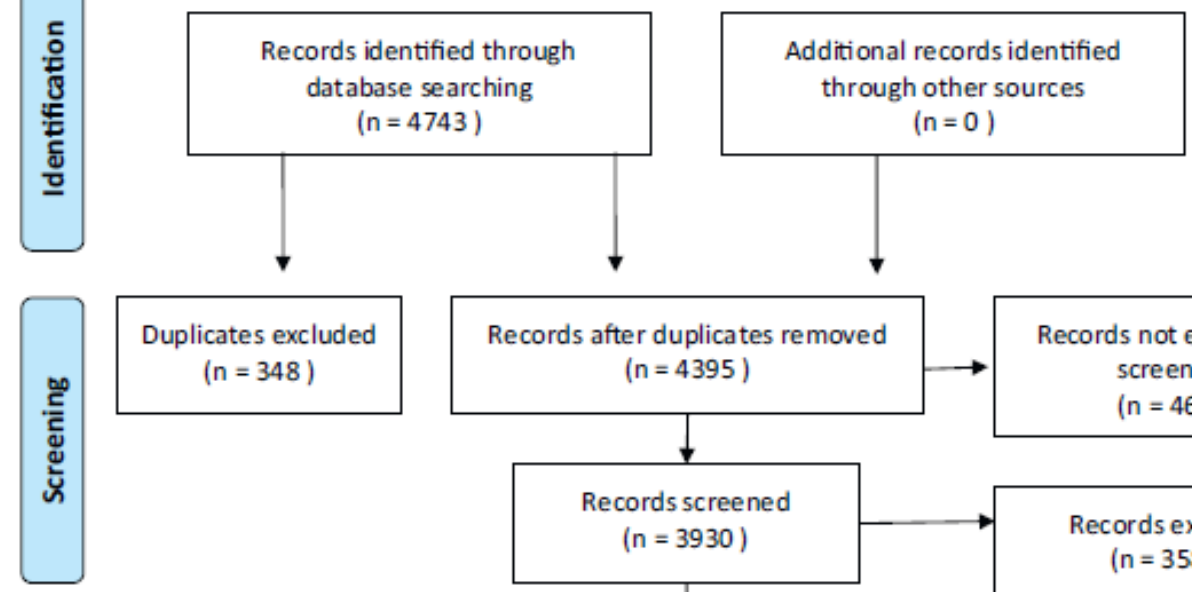

Duplicates excluded $(\mathrm{n}=348$ )
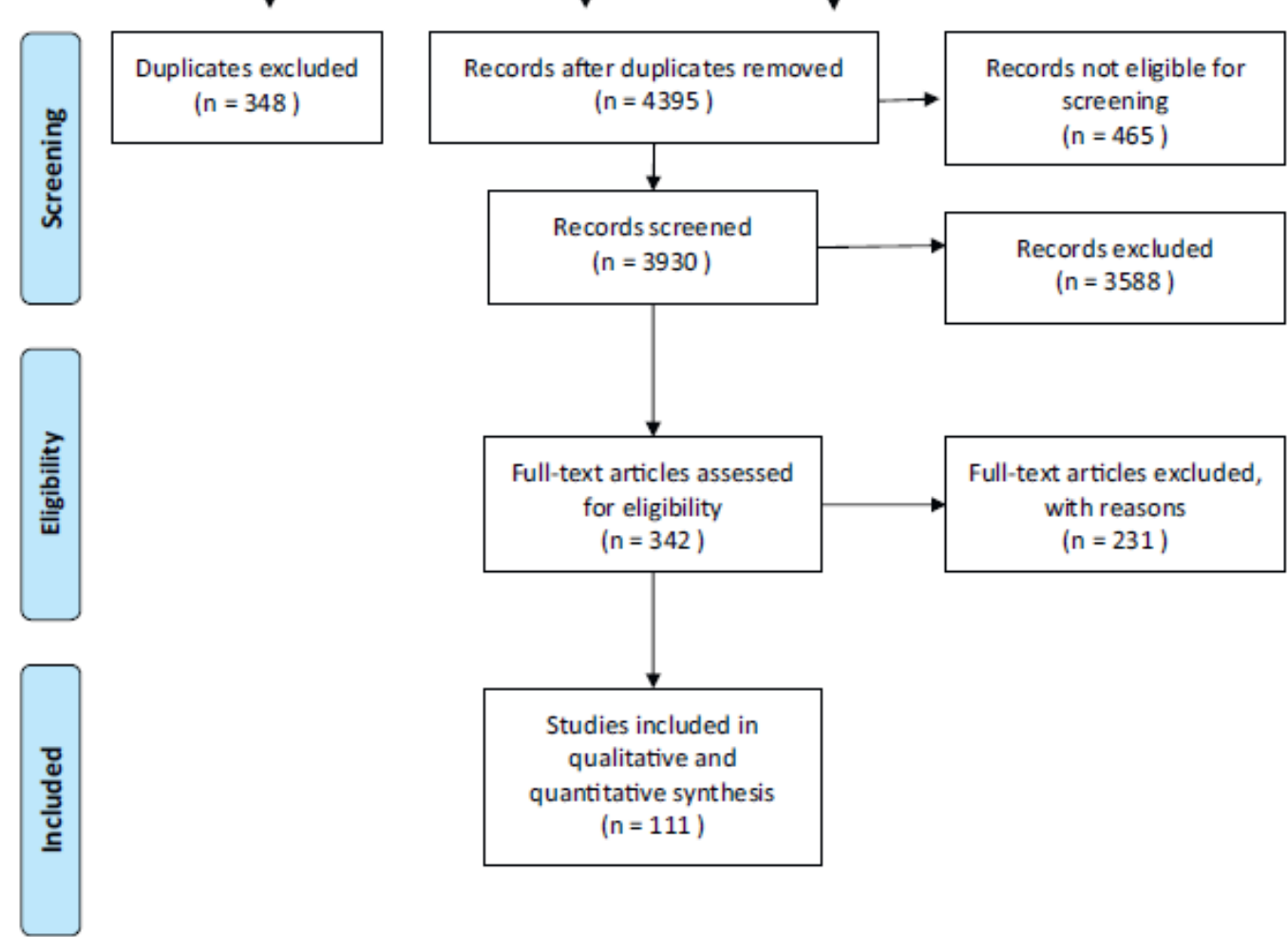

Fig. 1. Flowchart for article selection, based on Ref. [25]. 
Silva, M.L., Perrier, L., Cohen, J.M., Paget, W.J., Mosnier, A., Späth, H.M. A literature review to identify factors that determine policies for influenza vaccination. Health Policy: 2015, 119(6), 697-708

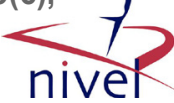

Table 1

Segments of the influenza vaccination policy chain, stakeholders involved, main information and factors influencing policy-making.

\begin{tabular}{|c|c|c|c|c|}
\hline Policy segment & Stakeholders involved & Main information used & Factors of influence & $\#$ \\
\hline $\begin{array}{l}\text { Vaccination } \\
\text { recommendations } \\
n-78,70 \%\end{array}$ & $\begin{array}{l}\text { (I) WHO, ECDC } \\
\text { (N) Ministry of Health, } \\
\text { Department of Health, } \\
\text { Governmental authority } \\
\text { (St) Advisory boards, } \\
\text { universities, Research } \\
\text { institutes }\end{array}$ & $\begin{array}{l}\text { Epidemiological and } \\
\text { virological studies, } \\
\text { Economic evaluations, } \\
\text { Models } \\
\text { i.e.: Australia, Canada, } \\
\text { France, Germany, India, } \\
\text { Italy, Netherlands, UK, US }\end{array}$ & $\begin{array}{l}\text { Ethics, } \\
\text { Vaccine } \\
\text { availability, Expert } \\
\text { opinion, } \\
\text { Media, } \\
\text { Political } \\
\text { willingness } \\
\text { i.e.: Australia, } \\
\text { Canada, China, } \\
\text { Israel, US }\end{array}$ & $\begin{array}{l}\text { (S) } 1,28,34,36,43,44,65,86, \\
93,103,109,107,110 \\
\text { (B) } 37,52,83,87 \\
\text { (P) } 02,03,05,07,08,10,12,13 \text {, } \\
14,15,19,20-22,24,25,27,31 \text {, } \\
32,35,38,39,40,41,45,46,47, \\
48,49,50,54,55,57,58,60,62 \text {, } \\
63,66,67,69,71,72,73,74,75 \text {, } \\
76,78,79,80,81,82,88,91,95 \text {, } \\
96,97,100,101,102,105,106\end{array}$ \\
\hline $\begin{array}{l}\text { Vaccine composition } \\
n-11,10 \%\end{array}$ & $\begin{array}{l}\text { (I) WHO } \\
\text { (St) NIC, WHOcc, } \\
\text { Surveillance networks, } \\
\text { Manufacturers }\end{array}$ & $\begin{array}{l}\text { Virological and } \\
\text { epidemiological studies, } \\
\text { Zoonotic studies } \\
\text { i.e.: EU, US }\end{array}$ & $\begin{array}{l}\text { Expert opinion } \\
\text { i.e.: US }\end{array}$ & $\begin{array}{l}\text { (S) } 6,29,42,90,108 \\
\text { (B) } 64 \\
\text { (P) } 4,53,56,59,98\end{array}$ \\
\hline $\begin{array}{l}\text { Vaccine license } \\
n-2,2 \%\end{array}$ & $\begin{array}{l}\text { (I) EMA } \\
\text { (N) Regulatory agency } \\
\text { (St) Advisory boards, } \\
\text { Manufacturers }\end{array}$ & $\begin{array}{l}\text { Vaccine safety, } \\
\text { Efficacy/effectiveness. } \\
\text { Cost-effectiveness, } \\
\text { Immunological studies }\end{array}$ & $\begin{array}{l}\text { International } \\
\text { pressure }\end{array}$ & $\begin{array}{l}\text { (S) } 89 \\
\text { (P) } 85\end{array}$ \\
\hline $\begin{array}{l}\text { Vaccine funding } \\
n-20,18 \%\end{array}$ & $\begin{array}{l}\text { (I) WHO } \\
\text { (N) Ministry of Health, } \\
\text { Governmental authority, } \\
\text { Healthcare providers } \\
\text { (St) Advisory boards, } \\
\text { Research institutes, } \\
\text { Manufacturers }\end{array}$ & $\begin{array}{l}\text { Epidemiological studies, } \\
\text { Economic evaluations, } \\
\text { Models } \\
\text { i.e.: Canada, EU, US }\end{array}$ & $\begin{array}{l}\text { Demographics, } \\
\text { Public opinion, } \\
\text { Budget, } \\
\text { Logistics } \\
\text { i.e.: Canada, UK, US, }\end{array}$ & $\begin{array}{l}\text { (S) } 33,51,70,77,92 \\
\text { (B) } 9 \\
\text { (P) } 11,16,17,18,23,26,30,61 \text {, } \\
68,84,94,99,104,111\end{array}$ \\
\hline
\end{tabular}

Key: \# number attributed to the article during full text reading (Annex 3);(I) actors at the international level; (N) actors at the national level; (St) stakeholders all levels; (S) seasonal influenza; (B) both seasonal and pandemic; (P) pandemic influenza; WHO, World Health Organization; ECDC, European Centre for Disease Control and Prevention; NIC, National Influenza Centre; EMA, European Medicines Agency; EU, European Union; UK, United Kingdom; US, United States. 
Silva, M.L., Perrier, L., Cohen, J.M., Paget, W.J., Mosnier, A., Späth, H.M. A literature review to identify factors that determine policies for influenza vaccination. Health Policy: 2015, 119(6), 697-708

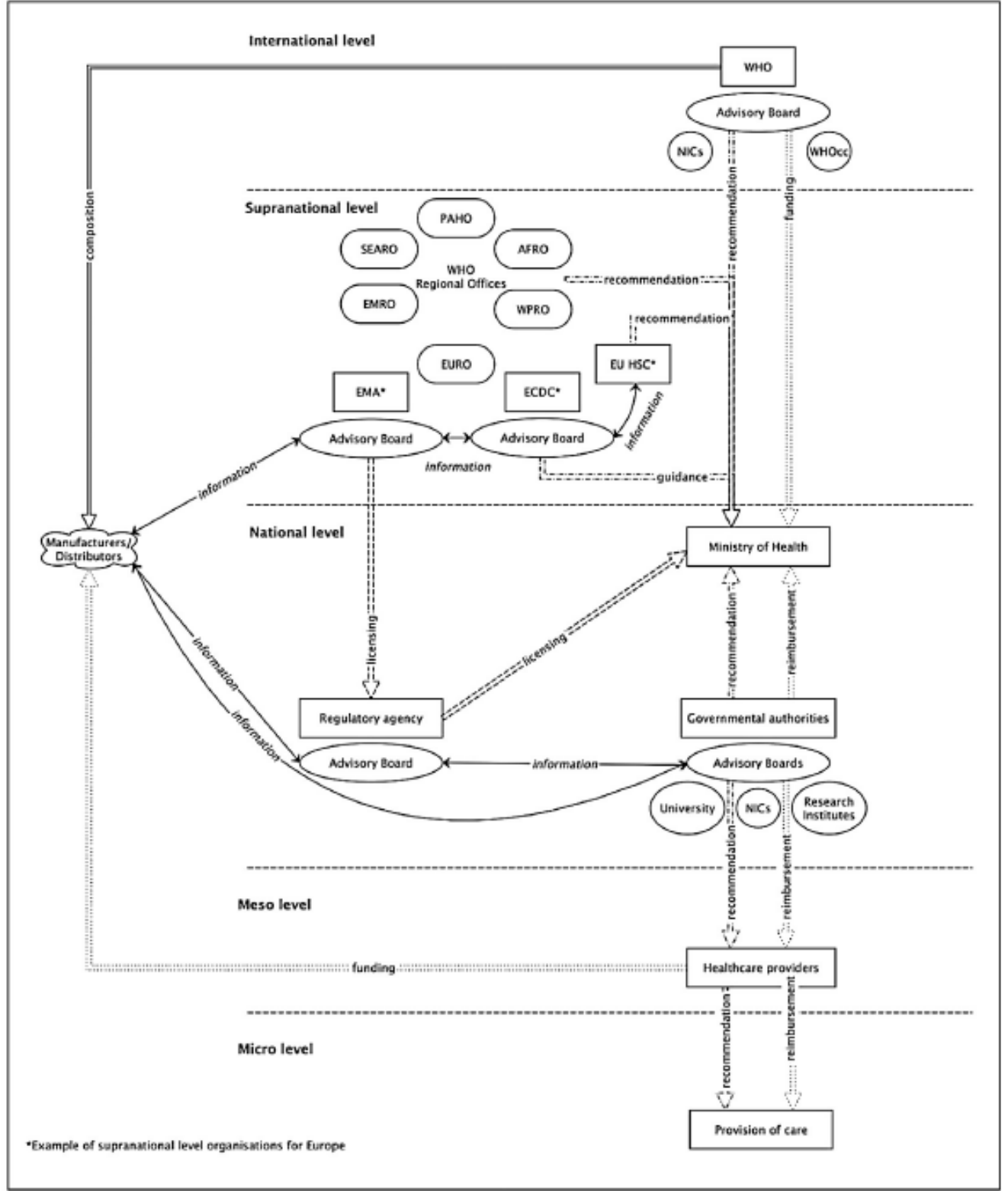

Key: WHOcc, World Health Organization collaboration centers; PAHO, Pan American Health Organization; AFRO, WHO Regional Office for Africa; SEARO, WHO Regional Office for South-East Asia; EMRO, WHO Regional Office for the Eastern Mediterranean; WPRO, WHO Regional Office for the Western Pacific; EURO, WHO Regional Office for Europe; NICs, National Influenza Centres; EU HSC*, European Union Health Security Committee; EMA*, European Medicines Agency; ECDC*, European Centre for Disease Prevention and Control; information, information exchange between the actors and stakeholders.

Fig. 2. General overview of the interactions between the stakeholders involved in the influenza vaccination policy chain, Key: WHOcc, World Health Organization collaboration centers; PAHO, Pan American Health Organization; AFRO, WHO Regional Office for Africa; SEARO, WHO Regional Office for South-East Asia; EMRO, WHO Regional Office for the Eastern Mediterranean; WPRO, WHO Regional Office for the Western Pacific; EURO, WHO Regional Office for Europe; NICs, National Influenza Centres; EU HSC*, European Union Health Security Committee; EMA*, European Medicines Agency; ECDC, European Centre for Disease Prevention and Control; information, information exchange between the actors and stakeholders, 